\title{
NASA Radioisotope Power System Program - Technology and Flight Systems
}

\author{
Thomas J. Sutliff* \\ NASA Glenn Research Center, Cleveland, Ohio 44135 \\ and \\ Leonard A. Dudzinski ${ }^{\dagger}$ \\ NASA Headquarters, Washington, DC 20546
}

\begin{abstract}
NASA sometimes conducts robotic science missions to solar system destinations for which the most appropriate power source is derived from thermal-to-electrical energy conversion of nuclear decay of radioactive isotopes. Typically the use of a radioisotope power system (RPS) has been limited to medium and large-scale missions, with 26 U.S. missions having used radioisotope power since 1961. A research portfolio of ten selected technologies selected in $\mathbf{2 0 0 3}$ has progressed to a point of maturity, such that one particular technology may be considered for future mission use: the Advanced Stirling Converter. The Advanced Stirling Radioisotope Generator is a new power system in development based on this Stirling cycle dynamic power conversion technology. This system may be made available for smaller, Discovery-class NASA science missions. To assess possible uses of this new capability, NASA solicited and funded nine study teams to investigate unique opportunities for exploration of potential destinations for small Discovery-class missions. The influence of the results of these studies and the ongoing development of the Advanced Stirling Radioisotope Generator system are discussed in the context of an integrated Radioisotope Power System program. Discussion of other and future technology investments and program opportunities are provided.
\end{abstract}

\section{Introduction}

Solar system exploration is a mainstay of the scientific program of robotic spacecraft missions conducted by NASA. To enable certain missions, power must be generated without the use of conventional photovoltaic methods. Use of radioisotope power systems has been firmly established since 1961 as a means to fulfill the need for such power among a variety of missions. Twenty-six missions have taken advantage of the investments of radioisotope power systems development to allow scientific exploration of destinations such as the moon, Mars, Jupiter, Saturn, and Pluto. Because of the longevity of radioisotope power systems, some of these missions have even continued to perform extended mission operations beyond the farthest reaches of the solar system.

The contemporary method of energy conversion for flight radioisotope power uses the Seebeck effect, in a thermoelectric (TE) energy conversion process. This method was first used in flight in 1961, and continues today as the means to power the Mars Science Lab rover. MSL uses the Multi-Mission Radioisotope Thermoelectric Generator (MMRTG), and is scheduled for launch in 2011. Thermoelectric energy conversion technology investments over the years have yielded more robust components that have a longer life. TE power systems have now been seen to demonstrate over 30 years of spaceflight operation on the two Voyager spacecraft, for example. While thermoelectric technology is well proven, it also has fairly poor conversion efficiency.

Investments seeking alternative energy conversion methods have been made over the years at both NASA and DOE. Most recently, NASA invested in a radioisotope power conversion technology program. A gas bearing, free piston Stirling conversion effort has matured through that program and has resulted in efficiency gains of 5:1 over thermoelectrics at the convertor level. Such promising performance in the technology program has also resulted in

\footnotetext{
"Program Manager, Advanced Flight Projects Office, 21000 Brookpark Rd.

${ }^{\dagger}$ Program Executive, Planetary Science Division, 300 E. St. SW
} 
this Stirling convertor being integrated and demonstrated in a system-level configuration known as the Advanced Stirling Radioisotope Generator (ASRG). An electrically heated ASRG, known as an Engineering Unit, has now operated over 3700 hours in a laboratory setting.

While a generator operating in controlled laboratory setting provides a strong indicator that the system is performing adequately, the ultimate rigorous assessment occurs when used in a space application. A goal of bringing any new technology to acceptance for mission use is to flight-demonstrate a system. While there are many approaches to demonstrating conventional systems, justifying such a demonstration flight for radioisotope power systems also requires the mission to be enabled or enhanced by its use. In short, a catch-22 occurs; a mission must be dependent on an RPS for its success, yet find acceptable the inherent performance uncertainty of using an unproven flight power system.

In 2008, NASA recognized this dilemma and solicited a series of studies to determine if there was sufficient diversity of missions that could use the new technology but do so within a higher risk classification of mission. As a result, the Discovery Scout Mission Capability Expansion (DSMCE) studies were solicited, selected, and conducted. Nine investigations, covering seven scientifically interesting destinations, were funded to conduct six-month studies to determine the likelihood of implementing a Discovery-class cost-capped mission. The results of those studies have now resulted in NASA stated intent to offer up to two ASRGs as government furnished equipment within an upcoming 2009 Discovery Announcement of Opportunity.

In parallel with the opportunity for principal investigators to propose use of ASRGs on a Discovery mission, the RPS program continues to ready the ASRG for possible spaceflight use. Lessons learned from an ASRG engineering unit, along with spaceflight system-level requirements have fed into the current ASRG project. The project is on track to deliver two systems for use on a potential mission that might be selected through the Discovery AO peer review process.

\section{History}

\section{A. Program}

Radioisotope power systems have enjoyed highly successful use in the U.S., having been used on 26 missions to date. First developed by the Atomic Energy Commission (AEC), the System for Nuclear Auxiliary Power (SNAP) program was formed. The original use of a SNAP-3B7 RPS dates back to 1961, aboard the Transit 4A navigation satellite operated in Earth orbit. Transit satellites were developed by the U.S. Navy for the early navigation satellite systems and were used by submarines and surface vessels. Transit was also known as the Navy Navigation Satellite (NNS). ${ }^{1}$ Since those first demonstrated uses, NASA, in partnership with the Department of Energy (DOE, after its transition from AEC), has deployed power systems on breathtaking missions to the moon, Mars, and the outer planets. These systems all have had the same technological heritage from 1961 and have served our exploration needs well.

Six basic configurations of RTG-based RPSs have been flown (SNAP-3, SNAP-9, SNAP-19, SNAP-27, MHWRTG, and GPHS-RTG). A seventh RTG configuration, the MMRTG, has been flight qualified for use yet has not begun its mission. All configurations of radioisotope power systems flown to date have been based on thermoelectric energy conversion. Some terrestrial research has been conducted on use of dynamic power conversion methods for radioisotope power systems, yet NASA has not flown such a system to date.

Plutonium-238 (Pu-238) has been used as the heat source for every NASA RPS flown. In 1988, the DOE ceased production of the fuel source for power systems. With the cessation of production, alternate sourcing of Pu- 238 has occurred, with over $25 \mathrm{~kg}$ of plutonium having been acquired from Russia to date. They too, however, appear to have no production capability in place and thus the supply is ultimately a limited one.

\section{B. Research and Technology}

Investments in RPS energy conversion technology have been a mainstay of the RPS program and the DOE partnership. Systematic research investments were made by NASA as far back as the 1980's. The goals of the radioisotope power technology portfolio have been to advance performance of RPS systems through the increase of energy conversion efficiency. The mission users benefit from such a gain in performance as the specific power (power per unit mass) gains are made and spacecraft can either be lighter, or they can carry and power more scientific payload. The effort to improve efficiency has taken on renewed significance with the increased constraint posed by a limited Pu-238 heat source supply. As a result a second criterion, specific power per unit mass of Pu-238 fuel, became more relevant.

Fundamentally, there has been a single method employed for the conversion of heat-of-decay to electrical power over the history of flight RPSs - Thermoelectrics. While TE systems are robust, they perform with low system 
efficiency. Efficiencies of about $6 \%$ are typical. In 2002, a NASA Research Announcement, Radioisotope Power Conversion Technology (RPCT), solicited research in RPS-based energy conversion. Ten RPCT NRA contracts were awarded in 2003 in the areas of Brayton, Stirling, thermoelectric (TE), and thermophotovoltaic (TPV) power conversion technologies. Of these ten, five were considered to be at an early preliminary research stage and five as advanced technology development projects. These ten promising research activities offered to improve performance over the then state-of-practice GPHS-RTG by reaching significantly higher energy conversion efficiencies, reducing the number of general purpose heat source (GPHS) modules required, and by obtain higher specific power performance. ${ }^{2}$ Directed research also was funded within NASA to integrate and augment the selected proposals.

The research portfolio has been adjusted over time to stress investments in areas that continued to show promising payoffs and suspended work in areas with less potential. In 2006, three remaining research areas were chosen to continue - development of advanced Stirling at Sunpower, demonstrate nanostructured TE at Boston College and MIT, and conducting TPV demonstrations at Creare. ${ }^{3}$ Of the three, the free piston Stirling work, conducted by Sunpower, Inc. was the most mature.

\section{Technology Insertion}

A significant challenge of any research program is to transition the results of research into a systems development activity. Even more difficult is the acceptance of a new technology by generally risk-averse spacecraft development teams. The Sunpower convertor technology was deemed ready to be inserted into a flight system generator configuration in 2005. Over the last four years convertor technology has been inserted into the Advanced Stirling Radioisotope Generator systems project.

\section{Current Status}

A new era is upon us where MMRTG is flight-ready, having been fueled and tested at DOE's Idaho National Laboratory (Fig. 1). The ASRG project is continuing its development at Lockheed Martin, in an effort led by DOE on NASA's behalf. The project has successfully developed an engineering-model class system, tested it to typical qualification levels, and assessed needed changes if such a system is to be produced for a future flight program. This electrically heated engineering model has been delivered to NASA Glenn Research Center where it has been placed on extended duration testing. The unit, shown in Fig. 2, has accumulated over 3700 hours of operation as of June 2009, while operating at a Stirling convertor hot-end temperature of $640 \mathrm{C}$. Power output of this system has remained stable around 135 We since being placed on test in November 2008.

But operation of an engineering model system in a laboratory setting is only one stepping-stone on the way to producing a system capable of flight on a NASA science mission. Two paths have been pursued to prepare ASRG for the possibility of use on future flight missions. First, the ASRG design must continue its maturation towards spaceflight standards. This is continuing through NASA's partnership with DOE. And second, an identified mission need was required. Of interest here is demonstrating a potential path to allow spaceflight demonstration of the ASRG at a sufficiently low

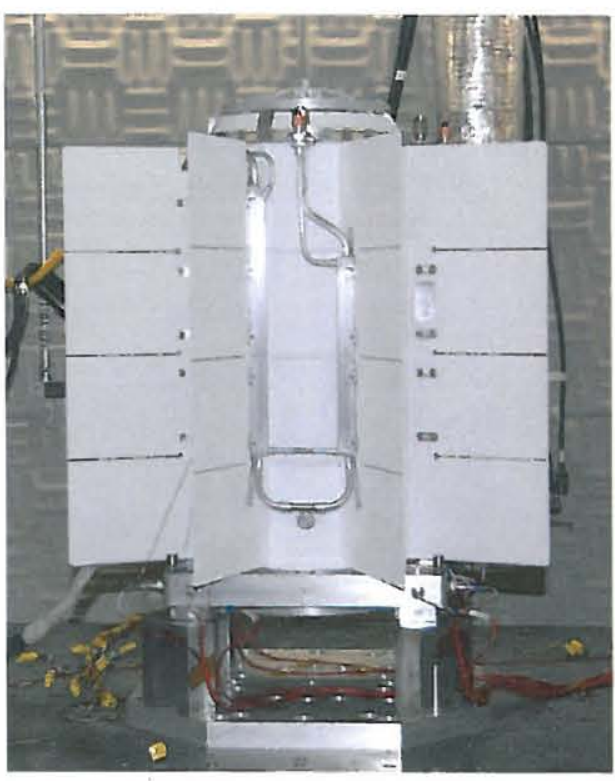

Figure 1. Flight Multi-Mission Radioisotope Thermoelectric Generator undergoing vibration acceptance testing at Idaho National Laboratory. enough mission risk. Successfully completing the engineering model ASRG proof-of-concept system led to a decision to solicit and fund mission studies that could benefit from a high efficiency RPS for missions to destinations not thought possible on cost-capped budget. These concept studies were known as Discovery and Scout Mission Capability Expansion (DSMCE) studies.

\section{A. DSMCE Studies}

In late Summer 2007, then NASA SMD Associate Administrator, Dr. Alan Stern, recognized the importance of readying ASRG for flight as quickly as practical, and identifying a potential opportunity to flight validate the 
ASRG. He had made a commitment to baseline MMRTG for the next potential outer planet flagship mission, being unwilling to risk a large mission on an unproven power system. At that time, the next Discovery mission was discussed as a potential opportunity for application of an ASRG on a mission with a scientific scope appropriate to make use of the new capability, yet being a small enough budgetary investment to make the mission risk acceptable. Dr. Stern and Planetary Science Division Director, Dr. James Green, conceived of the Discovery and Scout Mission Capability Expansion Program (DSMCE), resulting in a plan to study whether the use of ASRG could enable exciting new science within the Discovery mission class. Through a NASA research announcement process ${ }^{4}, 40$ proposals were received, and NASA awarded nine 6month mission concept studies to assess the potential science return, mission cost, and ASRG constraints imposed on a Discovery ASRG mission to be launched in 2014-2015. The nine mission concepts studied are summarized in Table 1. NASA was encouraged by the diversity of mission concepts received, and the awards spanned the range of possible targets: from orbiters to landers (and a boat), from the inner solar system, to the Moon, Mars, asteroids, comets, and the outer planets.

Eight of the nine studies were completed by early March of 2009. (The ninth one was completed in June due to a delay in funding the study). The aggregate conclusion of the nine studies was that the use of ASRG would enable exciting new science by opening up the solar system to the Discovery-class of missions. Information provided assisted in determining whether a nuclear mission, with all the associated integration issues, NEPA, and

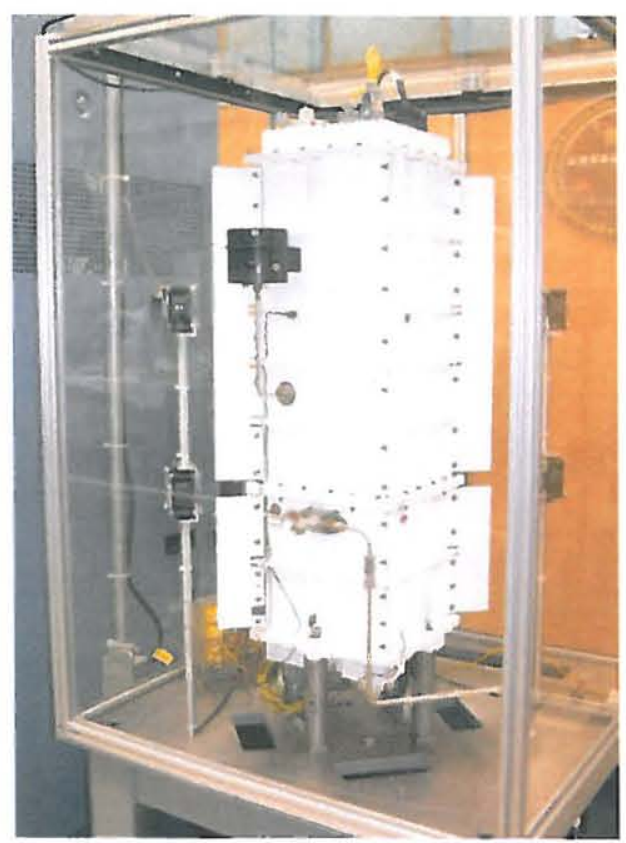

Figure 2. Advanced Stirling Radioisotope Generator Engineering Unit on extended life testing at GRC.

Table 1. DSMCE Mission Studies

\begin{tabular}{||l|l|l||}
\hline \hline $\begin{array}{l}\text { Destination } \\
\text { (Platform) }\end{array}$ & Study Title & $\begin{array}{l}\text { Principle Investigator } \\
\text { (Institution) }\end{array}$ \\
\hline $\begin{array}{l}\text { Moon } \\
\text { (Mobile Lander) }\end{array}$ & $\begin{array}{l}\text { ExoMoon: ASRG-Powered Lunar Polar } \\
\text { Exploration }\end{array}$ & $\begin{array}{l}\text { Dr Richard Elphic } \\
\text { (LANL) }\end{array}$ \\
\hline $\begin{array}{l}\text { Moon } \\
\text { (Rover/Comsat) }\end{array}$ & JEDI: A Lunar Polar Volatile Explorer & $\begin{array}{l}\text { Dr Bradley Jolliff } \\
\text { (Washington U) }\end{array}$ \\
\hline $\begin{array}{l}\text { Titan } \\
\text { (Boat) }\end{array}$ & Titan Mare Explorer (TiME) & $\begin{array}{l}\text { Dr Ellen Stofan } \\
\text { (Proxemy Research) }\end{array}$ \\
\hline $\begin{array}{l}\text { Io } \\
\text { (Fly-Bys) }\end{array}$ & Io Volcano Observer (IVO) & $\begin{array}{l}\text { Dr Alfred McEwen } \\
\text { (U of Arizona) }\end{array}$ \\
\hline $\begin{array}{l}\text { Trojan } \\
\text { (Lander) }\end{array}$ & $\begin{array}{l}\text { ASRG-Enabled Trojan Asteroid Mission } \\
\text { (Ilion) }\end{array}$ & $\begin{array}{l}\text { Dr Andrew Rivkin } \\
\text { (JHU/APL) }\end{array}$ \\
\hline $\begin{array}{l}\text { Comet } \\
\text { (Lander) }\end{array}$ & Comet Hopper (CHopper) & $\begin{array}{l}\text { Dr Jessica Sunshine } \\
\text { (U of Maryland) }\end{array}$ \\
\hline $\begin{array}{l}\text { Comet } \\
\text { (Sample Return) }\end{array}$ & Comet Coma Sample Return Mission & $\begin{array}{l}\text { Dr Scott Sandford } \\
\text { (ARC) }\end{array}$ \\
\hline $\begin{array}{l}\text { Mars } \\
\text { (Lander Drill) }\end{array}$ & Kuklos: A tour through martian history & $\begin{array}{l}\text { Dr Michael Hecht } \\
\text { (JPL) }\end{array}$ \\
\hline $\begin{array}{l}\text { Venus } \\
\text { (Balloons (2)) }\end{array}$ & $\begin{array}{l}\text { Dr Kevin Baines } \\
\text { (JPL) }\end{array}$ \\
\hline
\end{tabular}


nuclear launch safety approval procedures, could fit within a Discovery-level budget range. The cost assessments provided by the DSMCE studies provided insight to allow NASA program decision makers to develop a cost cap for a 2009 Discovery mission Announcement of Opportunity (AO) to enable ASRG mission proposals to be viable. NASA SMD Associate Administrator, Dr. Ed Weiler accepted the recommendation of Dr. James Green to open up the Discovery 2009 AO to ASRG mission proposals. Under the plan, missions may propose to baseline for use up to two ASRGs, which would be provided as government-furnished-equipment. Proposing use of an ASRG capability for the Discovery 2009 AO is constrained to missions that would be enabled by a RPS. Furthermore, the Discovery program will provide the necessary mission support, such as NEPA compliance and nuclear launch safety approval, which will not count against the cost cap of $\$ 425 \mathrm{M}$ (which also does not include launch vehicle service costs). The Discovery AO is anticipated to be released in late 2009. As with all PI-led missions, the selection of a baseline mission will be based primarily on science and likely achievement of the PI-defined science objectives.

Should an ASRG mission be selected by NASA after completing required environmental impact documentation and considerations, the first use of this new radioisotope power system could occur as early as 2014. If successful, the ASRG could power a revolution in deep space exploration. ASRG could enable smaller, more agile, more frequent missions to destinations beyond Jupiter, and to regions of the inner solar system where the Sun's insolation is to infrequent or too obscured to make photovoltaic power practical. More importantly, a successful ASRG capability would stretch the limited supply of Pu-238 to provide power for more missions. Because of the higher efficiency of the Stirling power conversion technology it is realistic to conceive of larger Stirling radioisotope systems that could power human exploration needs, as well as enable radioisotope electric propulsion. The ASRG is both a critical capability, and an exciting new opportunity for future exploration.

\section{B. ASRG Flight Preparations}

An Advanced Stirling Radioisotope Generator (ASRG) project was initiated between the Department of Energy and NASA. The project is proceeding on a flight systems development path to maintain the option of producing two flight-worthy generators in time for potential use by a mission user in the 2014 timeframe. The ASRG project team consists of an integrating contractor, Lockheed Martin, and other team members. A key subcontract supplier to LM is Sunpower. Sunpower would provide a pair of Advanced Stirling Convertors (ASC) that would be the energy conversion engines of the generator. Each engine would convert the heat of decay from plutonium to an $\mathrm{AC}$ electrical output. An ASRG Control Unit would provide the active feedback control to the ASC pair, convert the AC power to DC for spacecraft use, and provide other housekeeping functions. A standard General Purpose Heat Source (GPHS-step 2) module would be used as the means to package and support the plutonium dioxide fuel.

The ASRG project has proceeded through a systems requirements review in May, 2009. A final design review is anticipated in 2010, with flight systems being available for a mission in late 2013.

The baseline performance values anticipated for the ASRG are shown in Table 2.

The most significant performance item that makes the NASA interest in using ASRG so great is the power produced per kilogram of Pu-238 used. Through the use of $0.88 \mathrm{~kg}$ of $\mathrm{Pu}-238$

Table 2: Advanced Stirling Radioisotope Generator performance baseline

\begin{tabular}{|l|l|}
\hline Design Life & 3 years storage +14 years mission \\
\hline Power & $145 \mathrm{We}$ (beginning of mission) \\
\hline Mass & $<24 \mathrm{~kg}$ \\
\hline Specific Power & $<6 \mathrm{We} / \mathrm{kg}$ \\
\hline Specific Power (fuel) & $>165 \mathrm{We} / \mathrm{kg}($ fuel) \\
\hline Size & $<77 \mathrm{~cm} \mathrm{x} 46 \mathrm{~cm} \mathrm{x} \mathrm{40} \mathrm{cm}$ \\
\hline
\end{tabular}

GPHS modules, the resulting specific power per $\mathrm{kg}$ of Pu-238 fuel is $165 \mathrm{~W} / \mathrm{kg}$ (fuel). Compared to an MMRTG with nominal power output of 120 We through the use of eight GPHS modules, the specific power (fuel) is 4.8 times greater than the current state-of-practice. With the limitation on plutonium availability for use in power systems, the ability to consider conducting more science investigations within a limited resource becomes readily apparent.

\section{Future Directions}

The RPS Program continues to assess mission concepts and potential power systems and technologies for such systems. Such advanced planning is necessary as the timeframe to develop new flight qualified radioisotope power systems generally exceeds the timeframe of smaller competed missions of the Discovery and New Frontiers class of PI-led missions. By diversifying the selection of possible systems available to the scientific community, a broader range of planetary science objectives can be considered. 
The RPS Program investments in advanced planning, fundamental research, technology development, and transition to future flight systems are of course constrained by budget realities. The program seeks to maintain a healthy balance of seed-corn research and maturation of high-potential technologies. Advancing systems to flight is an expensive proposition and not to be entered into lightly. However, it is necessary to initiate development of such flight systems at a timeframe that precedes specific mission definition, as the flight qualification path of an RPS involves steps not conventionally implemented on cost-capped and competed missions.

\section{A. Technology Planning}

It is anticipated that the RPS Program will invest in a research portfolio solicitation in the 2013-2015 timeframe. Much like the RPCT NRA of 2002, both emergent research areas and focused maturing technologies are likely to be solicited. Definition of specific topical areas is likely to be guided by mission needs assessments that continue to be conducted.

\section{B. Mission Planning}

Potential mission opportunities and systems for them are identified through mission system studies, and are reported in the open literature. ${ }^{5}$ On-going studies and scientific inputs from the community will influence updates to such possible mission sets. A formal update to the 2005 RPS mission studies is underway.

\section{Systems development}

The Radioisotope Power System program anticipates maintaining the MMRTG capability for future mission needs. Once proven, the program expects to also maintain the ASRG capability. Based on science community inputs, the program is considering a Small RPS capability using either thermoelectric or Stirling-based energy conversion technologies. The potential systems are truly based upon guidance derived from the mission planning sets and science user inputs. The timing of developing new systems for missions will be based on identification of missions who are enabled by or significantly enhanced by the use of an RPS.

\section{Conclusion}

Radioisotope Power Systems have been successfully used in spaceflight applications for nearly 50 years. This success has relied on a thermoelectric energy conversion technology approach taking the heat of decay from Plutonium-238 and converting it to electrical energy. With the supply of Pu-238 diminishing, and a potential production capability not yet in-place, the development and deployment of a higher efficiency Stirling cycle energy conversion technology approach has taken on a greater imperative.

NASA and DOE are proceeding with a capability to flight demonstrate a Stirling-based generator for spaceflight use through the use of a two-part investment. DOE continues to prepare the Advanced Stirling Radioisotope Generator design for potential flight use. NASA is actively engaging the science community to ensure the ASRG is given appropriate consideration for future science mission applications when radioisotope power is necessary to enable exploration of the solar system.

\footnotetext{
References

${ }^{1}$ Transit: http://www.astronautix.com/project/transit.htm

${ }^{2}$ An Overview and Status of NASA's Radioisotope Power Conversion Technology NRA, AIAA-2005-5713, Anderson, D.J., Wong, W. A., Tuttle, K.L., 2005

${ }^{3}$ Overview of NASA Program on Development of Radioisotope Power Systems with High Specific Power, AIAA 20064187, Mizra, A.K., 2006

${ }^{4}$ DSMCE studies selections, Solicitation: NNH07ZDA001N-DSMCE, https://nspires.nasaprs.com/; Apr 08, 2008

${ }^{5}$ Extending Exploration with Advanced Radioisotope Power Systems, JPL D-28903, 2005
} 